
\title{
25 Research Square \\ Decrease of Consciousness Level Caused by Baclofen; a Case Report
}

\section{Hamideh Ebrahimi}

Shahid Beheshti University of Medical Sciences School of Nursing and Midwifery https://orcid.org/0000-0001-8032-9305

Meimanat Hosseini ( $\nabla$ meimanathosseini@yahoo.com )

Shahid Beheshti University of Medical Sciences School of Nursing and Midwifery

\section{Case report}

Keywords: Consciousness, baclofen, Case report, Gamma-aminobutyric acid agonist, Chronic spasm

Posted Date: November 15th, 2021

DOl: https://doi.org/10.21203/rs.3.rs-877940/v1

License: (1) This work is licensed under a Creative Commons Attribution 4.0 International License. Read Full License 


\section{Abstract}

Background: The side effects of drug use can have different consequences, from allergies to death. Among the drugs used to relieve chronic spasms is baclofen. Baclofen is a gamma-aminobutyric acid (GABA) agonist that is commonly administered orally and acts on the spinal cord. A few studies have been reported on mortality from baclofen.

Case presentation: This present study reported a case of decreased consciousness and drowsiness, and severe decrease in muscle tone as a result of taking only $50 \mathrm{mg}$ of baclofen.

Conclusion: Level of consciousness can be decreased following the administration of baclofen but it is not permanent. Nurses are recommended to check albumin level of the blood as an intervening factor and pay attention to patients' responses to baclofen.

\section{Background}

The side-effects of drugs can have a wide range of effects from allergy to death. Totally, sometimes of drug side-effects cause permanent debilitation in patients so that a study reported that the risk of death in patients who experienced drug side-effects was about twice the patients who had no drug side-effects [1]. In addition, nurses are the largest group of professional health personnel as the frontline of health care systems. They undertake several and diverse roles and this diversity and complicacy of roles makes nursing a professional activity that requires responsiveness, accuracy, and sharpness. Any shortage and imperfection in nursing education surely affect the quality and quantity of health services and public health consequently [2]. Among many, one of nursing tasks is to diagnose the side-effects of drugs. With the introduction of many new drugs with more benefits for patients, the risk of drug side-effects and the consequential costs and complications has also increased [3]. Among the drugs available for chronic spasms, baclofen is an agonist gamma- amino- butric acid (GABA) that is normally prescribed as an edible drug that affects the spinal cord. The drug also affects generalized and chronic spasms like MS. As an agonist GABA, it affects pre/post synaptic receptor (pre synaptic/post synaptic) and causes hypopolarization of the membrane. That is, as to pre-synaptic, the drug decreases the penetration of calcium and through this, decreases discharge of glutamic stimulation transmitter. In the case of post-synaptic, it facilitates the inhibiting effect of GABA [4]. The drug is recommended to treat alcohol dependency and spasms with spinal cord region. Recently, it has been used to treat hiccup with different etiologies in anxiety disorder cases. Its absorption happens in the digestive system, $70-80 \%$ of it is discharged by the kidneys, and the rest is metabolized by the liver and digestive system. The half-life of the drug is about $4 \mathrm{hrs}$, which is longer in individuals with kidney failure. The drug is available at 10 and $25 \mathrm{mg}$ doses and the maintenance dose is normally $80 \mathrm{mg} /$ day [5]. It is a lipophile and can cross blood-brain barrier (BBB); therefore, high doses poisoning causes side effects like coma, seizure, apnea, and cardiac conduction disturbances [6]. While there are a few studies on the mortality rate caused by using baclofen, according to the North America Poison Information and Statistic Center, in six death cases, baclofen was the first cause and in 10 death cases, it was the co-cause factor. The majority of available reports are about 
poisoning with $270 \mathrm{mg}<$ doses and poisoning cases with less than $270 \mathrm{mg}$ doses are rarely studied [7]. In Iran, we found a case of a 76 years old woman who had a decrease in consciousness level due to using $75 \mathrm{mg}$ of the drug in fall 2020 [8]. There was another case of decreased consciousness level in 28 years woman in Mashhad in spring 2020 that used $10 \mathrm{mg}$ dose of baclofen $(100 \mathrm{mg} /$ day), who was recovered after 48hr hospitalization in the coronary care unit (CCU) [9]. In light of this, the present study reports a decreased consciousness level, sleepiness, and severe decrease in muscle power due to using 50mg baclofen. Therefore, the present study reported a case of decreased consciousness and drowsiness, and a severe decrease in muscle tone as a result of taking only $50 \mathrm{mg}$ of baclofen.

\section{Case Presentation}

A 75 years old woman with weight about $50 \mathrm{~kg}$ has a cardiac and respiration arrest and decreased consciousness level following internal bleeding caused by a car accident. Sonography results showed that one of the kidneys is functional. The patient has a history hypertension and an open-heart surgery. During nine months of hospitalization, tracheostomy and PEG was carried out and Central vein line was placed. During the past six months, the patient has been under home ICU care and received nursing care. Currently, the patient has acute limbs spasms and breathes intentionally without supplementary oxygen through a respiratory track. The saturation oxygen level of the patients is $97-100 \%$ and she receives Ritalin (5mg), Clexane injection (40mg), Plavix $(75 \mathrm{mg})$, atorvastatin $(10 \mathrm{mg})$, normal saline serum ( $1500 \mathrm{cc} / 24 \mathrm{~h})$, sodium chloride ( $15 \%$ - $20 \mathrm{cc}$ ), potassium chloride ( $5 \mathrm{cc}, 15 \%$ with the serum), sodium valproate $600 \mathrm{mg} / 24 \mathrm{~h}$, captopril $(75 \mathrm{mg} / 24 \mathrm{~h})$, prazosin $(1 \mathrm{mg} / 24 \mathrm{~h})$, amlodipine $(5 \mathrm{mg}$, in the case of systolic blood pressure $>160$ ), and carvedilol 6.25 (in the case of heartbeat $>80$ ). Our examination of other vital signs indicated a few fever periods and sputum and urine cultures were positive several times and antibiotics were prescribed based on the culture results. The pupils and corneas react to light, while the patient is not able to follow the light or have a meaningful look. In response to painful stimulation, the patent tries to localize and remove the limp. Because of long-term rest in bed, the patient suffers severe spasm and muscle deformity at the upper and lower limbs. Physiotherapy was prescribed for the patients with bracing and skin traction. To solve the severe spasm of upper and lower limbs the attending physician prescribed baclofen $25 \mathrm{mg} / 12 \mathrm{hr}$ and after taking two doses, the patient's level of consciousness decreased in 24hrs with sleepiness and acute loosen muscles of the upper and lower limbs. The patients did not respond to audio stimulations and the pupils had no reaction to light. There was no change in saturated oxygen level and without oxygen saturation was $96 \%$. The patient did not have fever, systolic blood pressure was in 120-190 range and diastolic blood pressure was in 70-110 range. Cardiac rhythm was sinusoidal without arrhythmia and the test result were read (Creatinine: 1.2, Albumin: 2.9, Blood urea nitrogen: 34, Blood sugar: 160, Na: 139, Hemoglobin: 9.1). The liver enzyme level, thyroid function tests, international normalized ratio, partial thromboplastin time, and prothrombin time were normal.

Because the patient had not recently received any new drug other than baclofen, it was stopped. To check for disorder, a brain scan was prescribed and the results indicated no notable point. Sixty hours after stopping baclofen, sleepiness was resolved and the consciousness level increased. The patient was able 
to open her eyes and react to sounds. The pupils and corneas also reacted to light, the loosen muscles were resolved, and limbs spasm recurred.

\section{Conclusions And Discussion}

To solve severe upper and lower limbs spasms, baclofen as an agonist GABA was used. The drug is recommended for chronic spasms with spinal cord sources. About $70-80 \%$ of the metabolic of the drug is in the kidney so that patients with kidney failure are at the risk of pharmaceutical poisoning [5]. Laren et al. reported baclofen poisoning in a 69 years old woman with kidney failure who used $40 \mathrm{mg} / \mathrm{day}$ of the drug and with $4 \mathrm{hrs}$ dialysis, the symptoms of decreased level of consciousness were resolved [10]. Here, the patients only had one functioning kidney since her birth; still, her creatinine serum and urea levels were normal with acceptable urine discharge. Therefore, there was no proof of kidney function disorder. In addition, blood albumin of the patient was $2 / 9$, which was below the normal level. Despite receiving three albumin vials (20\%) per week, serum level of the drug was not adjusted. Since albumin is one of the most common protein in blood and transfers the majority of drugs in the plasma, albumin level has a notable effect on drug pharmacology and pharmacokinetic in plasma [11]. Therefore, it can have a role on the patient poisoning in this report. Nurses are recommended to check albumin level of the blood as an intervening factor and pay attention to patients' responses to baclofen.

\section{Abbreviations}

GABA: Gamma-aminobutyric acid; CCU: coronary care unit; BBB: blood-brain barrier

\section{Declarations}

\section{Acknowledgements}

Not applicable.

\section{Authors' contributions}

$\mathrm{HE}$ and $\mathrm{MH}$ examined and treated the patient. $\mathrm{HE}$ and $\mathrm{MH}$ wrote the manuscript and made all the figures. $\mathrm{HE}$ and $\mathrm{MH}$ advised on treatment protocol. NO supervised the manuscript. All authors read and approved the final manuscript.

\section{Funding}

None

\section{Availability of data and materials}

Not applicable. 


\section{Ethics approval and consent to participate}

Our institution's Research Ethics Board does not require a review or approval for case reports.

\section{Consent for publication}

The patient consented to the publication of this case report and written informed consent was obtained from the patient.

\section{Competing interests}

The authors declare that they have no competing interests.

\section{References}

1. Golder S, Loke YK. Sources of information on adverse effects: a systematic review. Health Info Libr J. 2010 Sep;27(3):176-90. https:// doi. org/10.1111/j.1471-1842.2010.00901.x.

2. Ravani Pour M, Vanaki Z, Afsar L, Azemian A. The standards of professionalism in nursing: the nursing instructors' experiences. Evid Based Care. 2014 Apr 1;4(1):27-40. https:// doi. org/10.22038/EBCJ.2014.2392

3. Salehifar E, Ala S, Gholami K. Knowledge, attitude and performance of pharmacists and nurses in Mazandaran province, Iran regarding adverse drug reaction and its reporting, 2005.. J Mazandaran Univ Med Sci. 2007; 16 (56): 115-125.

4. Chrousos GP, Katzung B, Trevor A. Basic and clinical pharmacology. Adrenocorticosteroids \& Adrenocortical Antagonists, 13th ed; McGraw-Hill Medical: New York, NY, USA. 2015:303.

5. Issa S, Hafez E, El-Banna A, Abdel Rahman S, AlMazroua M, El-Hamd M. Baclofen systemic toxicity: Experimental histopathological and biochemical study. Hum Exp Toxicol. 2018;37(4):431-41. https:// doi. org/10.1177/0960327117712369

6. Srivastava S, Hoon A, Ogborn J, Johnston M. Acute onset rhythmic hiccup-like respirations secondary to oral baclofen toxicity. Pediatr Neurol. 2014;51(2):252-4. https:// doi. org/10.1016/j.pediatrneurol.2014.03.015.

7. Jamshidi N, Morley KC, Cairns R, Dawson A, Haber PS. A review of baclofen overdoses in Australia: calls to a Poisons Information Centre and a case series. Alcohol Alcohol. 2019;54(1):73-8. https:// doi. org/10.1093/alcalc/agy082.

8. Abdi M, kramizadeh K. The Effect of Baclofen on the Reduction of the Level of Consciousness: A CaseReport. Yafteh. 2020;1(22):49-55.

9. MoradiE V, Ghasemi T, Sadrzadeh S, Mousavi S. Intoxication with Low-Dose Baclofen: A Case Report. Journal of Fasa University of Medical Sciences.2020;10(3):2404-2407.

10. Porter LM, Merrick SS, Katz KD. Baclofen toxicity in a patient with hemodialysis-dependent end-stage renal disease. J Emerg Med. 2017;52(4):e99-e100. 
11. Otagiri M. A molecular functional study on the interactions of drugs with plasma proteins. Drug Metab Pharmacokinet. 2005;20(5):309-23. https:// doi. org/ 10.2133/dmpk.20.309. 